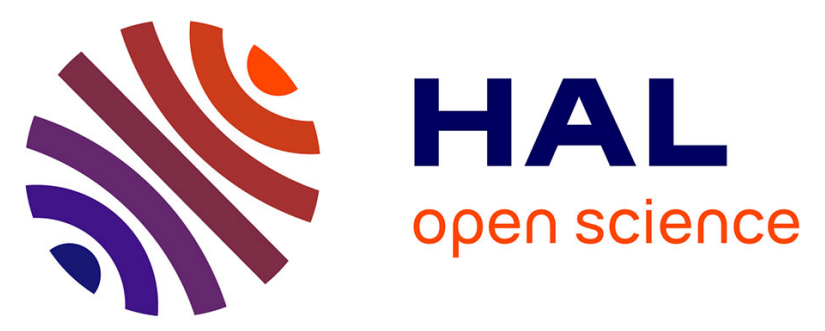

\title{
Processing and properties of metal matrix composites reinforced with continuous fibres for the control of thermal expansion, creep resistance and fracture toughness
}

F. Delannay, C. Colin, Y. Marchal, L. Tao, F. Boland, P. Cobzaru, B. Lips, M.-A. Dellis

\section{To cite this version:}

F. Delannay, C. Colin, Y. Marchal, L. Tao, F. Boland, et al.. Processing and properties of metal matrix composites reinforced with continuous fibres for the control of thermal expansion, creep resistance and fracture toughness. Journal de Physique IV Proceedings, 1993, 03 (C7), pp.C7-1675-C7-1684. 10.1051/jp4:19937263 . jpa-00251903

\section{HAL Id: jpa-00251903 https://hal.science/jpa-00251903}

Submitted on 1 Jan 1993

HAL is a multi-disciplinary open access archive for the deposit and dissemination of scientific research documents, whether they are published or not. The documents may come from teaching and research institutions in France or abroad, or from public or private research centers.
L'archive ouverte pluridisciplinaire HAL, est destinée au dépôt et à la diffusion de documents scientifiques de niveau recherche, publiés ou non, émanant des établissements d'enseignement et de recherche français ou étrangers, des laboratoires publics ou privés. 


\title{
Processing and properties of metal matrix composites reinforced with continuous fibres for the control of thermal expansion, creep resistance and fracture toughness
}

\author{
F. DELANNAY, C. COLIN ${ }^{(1)}$, Y. MARCHAL, L. TAO, F. BOLAND, P. COBZARU, B. LIPS and \\ M.-A. DELLIS
}

Université Catholique de Louvain, Département des Sciences des Matériaux et des Procédés, PCIM, Place Sainte Barbe 2, 1348 Louvain-la-Neuve, Belgium

\begin{abstract}
$\mathrm{Al}-, \mathrm{Zn}$, and Cu-based matrix composites reinforced with continuous fibres of carbon, $\mathrm{SiC}, \mathrm{Al}_{2} \mathrm{O}_{3}$, or steel have been processed by squeeze casting or powder metallurgy. Interface reactions can be controlled by alloying additions in the matrix. Interface adhesion has been characterized from the distributions of fibre pull-out lengths on fracture surfaces. Thermal expansion curves reveal the magnitude of the stress transfer at interfaces. In the case of low melting point matrices, ductile steel fibres offer the best combination of fracture toughness and creep resistance.
\end{abstract}

\section{INTRODUCTION}

Continuously reinforced metal composites have been much less studied than discontinuously reinforced composites. Indeed, discontinuously reinforced aluminium composites are now produced at relatively low cost, which justifies the increasing interest that these materials are gaining in engineering design. In contrast, the use of metal composites reinforced with continuous fibres remains quite limited. This paper aims at showing that reinforcing an alloy with continuous fibres can make sense even in the case of relatively low cost matrix alloys. Indeed, fibres and processing methods can be used whose cost remains compatible with the price of such alloys.

This contribution is based on the experience that the authors have acquired on the processing and properties of a variety of continuously reinforced metal composites : Cu-based alloys reinforced with carbon fibres, Al-based alloys reinforced with $\mathrm{SiC}$, carbon, or stainless steel fibres, and $\mathrm{Zn}$-based alloys reinforced with $\mathrm{Al}_{2} \mathrm{O}_{3}$, carbon, or steel fibres. A review will be given of the basic understanding which has been obtained on these materials. Discussion will focus successively on the processing methods, the assessment of interface bonding strength, the shape of thermal expansion curves, the variables affecting fracture toughness, and the creep strengthening.

(1)

On leave from Ecole Nationale Supérieure des Mines de Paris, Centre des Matériaux P.M. Fourt 


\section{PROCESSING METHODS}

Metal matrix composites can be processed in the liquid state or in the solid state. The easiest and cheapest method for processing continuously reinforced composites with $\mathrm{Al}$-based or $\mathrm{Zn}$-based matrices is by liquid metal infiltration using squeeze casting or pressure die casting. Powder metallurgy is better for higher melting point alloys such as Cu-based alloys. In both liquid state and solid state methods, interface adhesion can be modified by additions of alloying elements in the matrix.

Figure 1 presents the scheme of the squeeze casting process [1]. A (preheated) fibre preform is placed in a (preheated) die immediately before (or immediately after) the pouring of the liquid metal. A pressure of $20 \mathrm{MPa}$ is applied by a punch with a displacement rate such as to achieve complete infiltration of the preform within a few seconds, $i$. e. before the beginning of solidification. In order to limit the extent of reaction at fibre/matrix interfaces, the die was designed to have a low thermal inertia and the specimen can be readily expelled from the die and quenched. The duration of the process from the beginning of the pouring of the liquid metal in the die can be less than 90 sec. Interface reaction can be further controlled by adjusting the temperatures of the liquid metal, of the preform, and of the die.

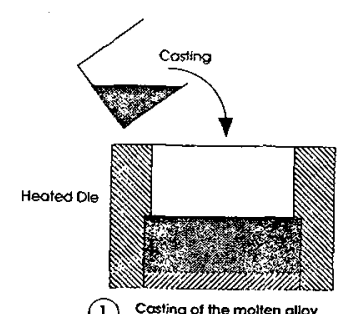

(1) Casting of the molten olloy

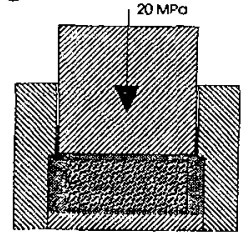

(3) Pressure Application (20MPa)

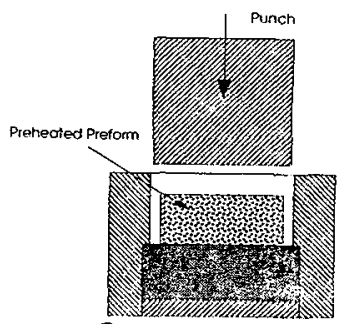

(2) Insertion of the prelorm

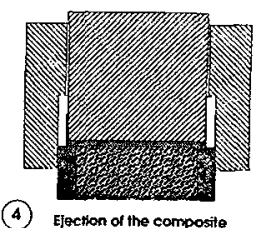

Figure 1 : Scheme of the squeeze casting set-up

The first condition for the success of casting methods is the quality of the fibre preform which must present a homogeneous distribution of the fibres with fully open porosity, together with a sufficient compression strength to avoid deformation or damaging during infiltration. Different methods have been designed for preparing preforms with controlled volume fraction and orientation of the fibres. Figure 2 presents some examples. In most cases, the fibre orientation was random in the plane of the preform. Alumina preforms were made by bonding Saffil fibres with an inorganic salt. Steel preforms were prepared by sintering compacted mats of fibres. Carbon felts were used as carbon fibre preforms with random orientation. Preforms with aligned fibres were made by winding coils of continuous fibres or by stacking layers of tissues.

The extent of interface reaction during squeeze casting varies very largely depending on the fibre/matrix association and on the processing conditions. Two extreme cases are compared in figure 3 : a pure aluminium matrix with stainless steel (316L) fibres [2] and a $\mathrm{Zn}+27 \% \mathrm{Al}$ foundry alloy (ZA27) with carbon fibres [3]. 
Owing to the reactivity between $\mathrm{Al}, \mathrm{Fe}, \mathrm{Ni}$, and $\mathrm{Cr}$, large rings of intermetallic compounds have grown around the fibres and the $\mathrm{Fe}-\mathrm{Al}$ eutectic phase is observed in the matrix together with large precipitates. In contrast, owing to the absence of chemical affinity between $\mathrm{Zn}$ and $\mathrm{C}$, no compound can be detected at the interfaces in $\mathrm{ZA} 8 / \mathrm{C}$ composites. It may be noticed in figures $3 \mathrm{~b}$ that the solidification process brings about a "natural" protection of the fibres : the Al-rich primary dendrites which solidify first leave the fibres surrounded by the Zn-rich eutectic phase which solidifies the last. This phenomenon is always observed.

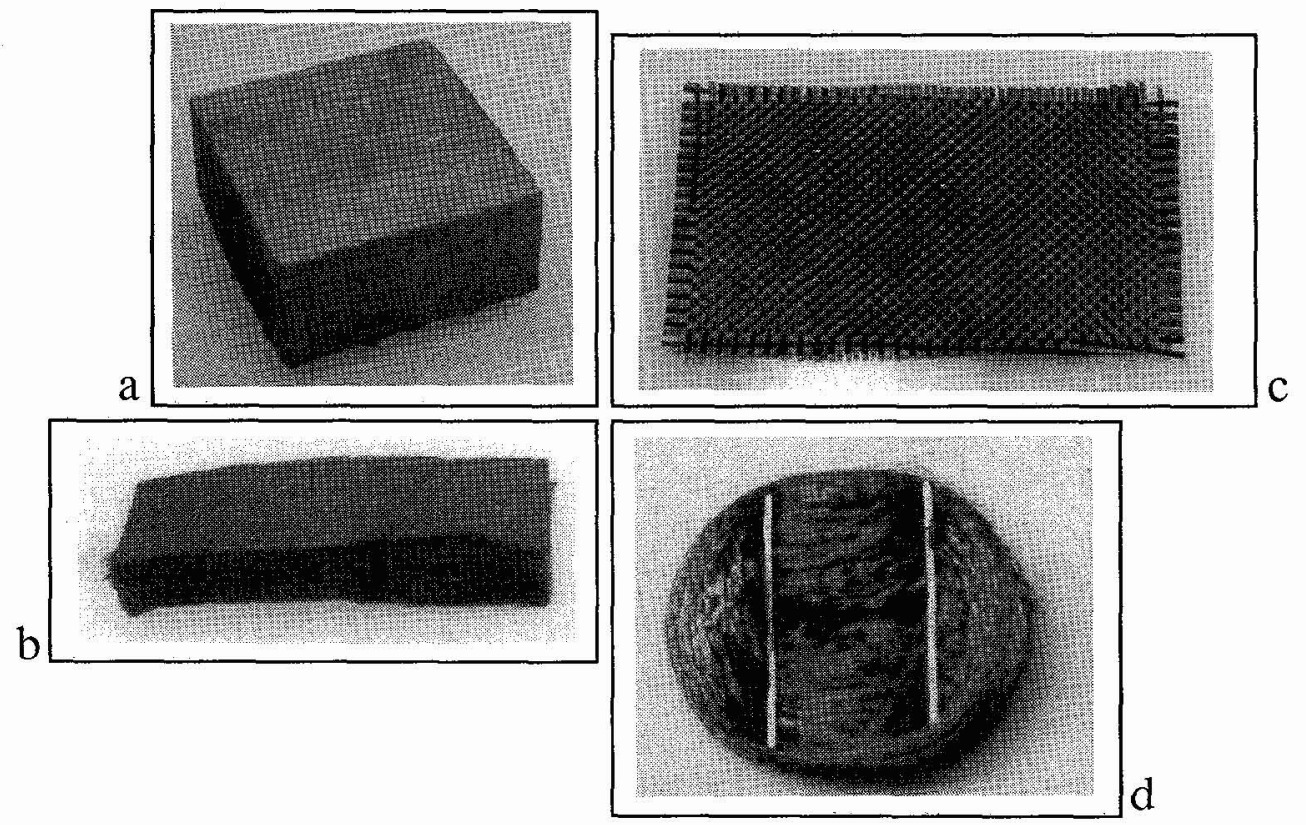

Figure 2 : Different types of preforms : a) sintered mat of steel fibres, b) carbon felt, c) carbon tissue, d) coil of continuous steel fibres

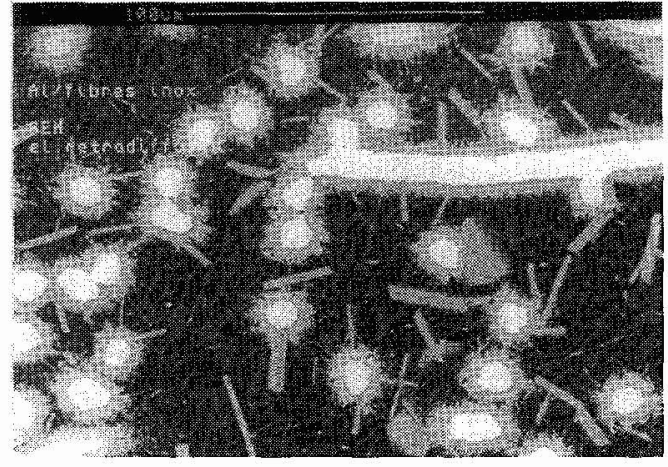

a

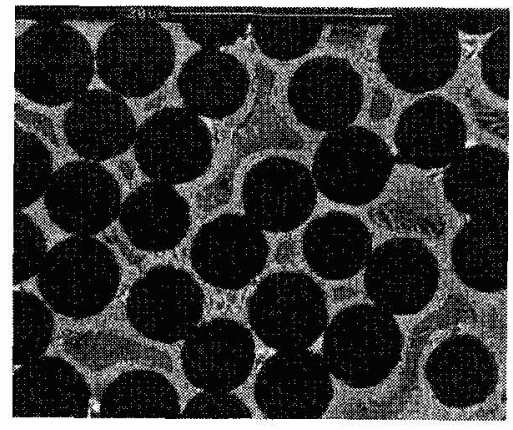

b

Figure 3: Extreme cases of interface reaction occuring during squeeze casting. a) $\mathrm{Al} / 316 \mathrm{~L}$; b) ZA27/carbon

The cooling rate after infiltration of the preform by the liquid metal affects very much the extent of interface reaction. Indeed, it has been observed that interface 
reaction develops essentially during the short interval of time before the solidification the matrix alloy [2]. As the solidification rate decreases from the die wall toward the center of the preform, composites associating highly reactive matrix/fibre couples can present large heterogeneities of microstructure. In figure $3 \mathrm{a}$, the micrograph of the $\mathrm{Al} / 316 \mathrm{~L}$ composite was taken in the middle of the preform (where the cooling rate is the lowest) in a composite prepared by casting in a die at $250^{\circ} \mathrm{C}$. In contrast, figure 4 presents two micrographs of the same composite $\mathrm{Al} / 316 \mathrm{~L}$ cast in a die at room temperature. Micrograph $4 \mathrm{a}$ was taken in the immediate vicinity of the die wall while micrograph $4 \mathrm{~b}$ was taken at the center of the preform (i.e. at a distance of $5 \mathrm{~mm}$ from the wall as the preform thickness was 10 $\mathrm{mm}$ in this case). Very little intermetallic compound has formed in the area close to the die wall where the duration of contact of the fibres with the liquid metal is the shortest. Actually, only very limited interface reaction was observed when preparing thin specimens with preform thicknesses of less than $2 \mathrm{~mm}$.

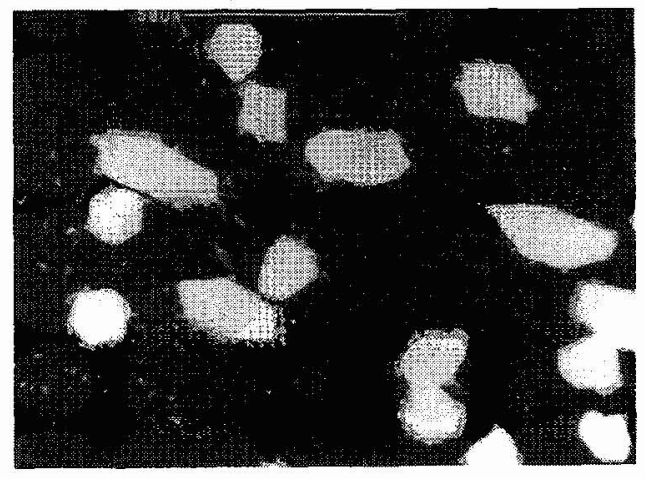

$\mathbf{a}$

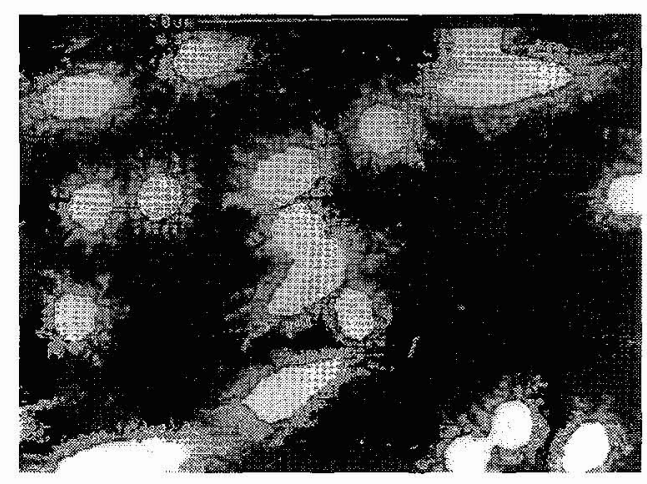

b

Figure 4 : SEM micrographs of a Al/316L composite cast in a cold die ; a) area close to the die wall ; b) area at $5 \mathrm{~mm}$ from the die wall.

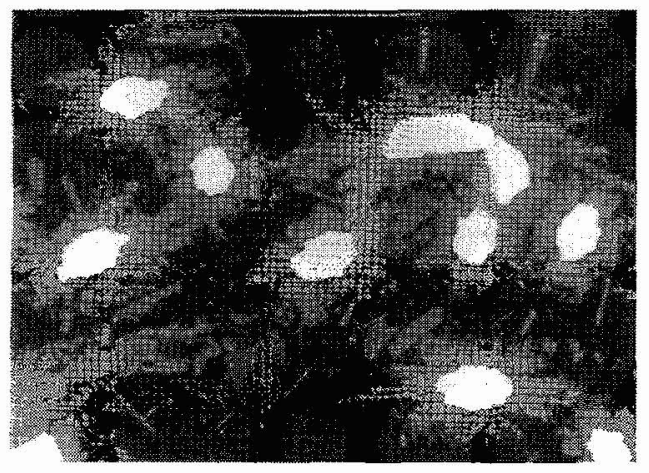

a

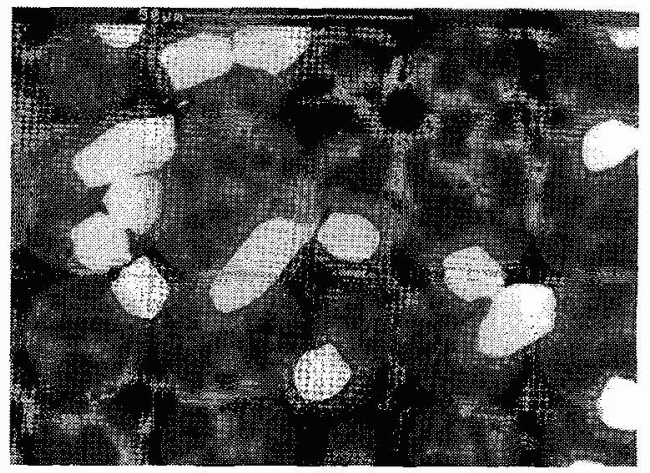

b

Figure 5 : SEM micrographs showing the variation of the extent of intermetallic formation around the fibres in $\mathrm{Al}+\mathrm{Zn} / 316 \mathrm{~L}$ composites processed under identical conditions. Zn content : a) $0 \%$; b) 25 wt \% 
The extent of interface reaction can also be controlled by alloying additions in the matrix. We have studied particularly the effect of additions of $\mathrm{Zn}$ in Al-base matrices. Indeed, $\mathrm{Zn}$ presents a much lower affinity than Al toward carbon or steel and, as mentioned previously, $\mathrm{Zn}$ forms with $\mathrm{Al}$ an eutectic phase which segregates around the fibres during solidification. Figure 5 illustrates the influence of $\mathrm{Zn}$ on the reactivity between an Al-based matrix and stainless steel fibres (316L). In a series of samples processed under identical conditions using preforms of $10 \mathrm{~mm}$ thickness, the size of the intermetallic ring forming around the fibres in the middle of the preform was observed to decrease rapidly as the $\mathrm{Zn}$ content of the matrix increased.

An alternative to squeeze casting for the processing of low melting point metal matrix composites is pressure die casting. Pressure die casting is much more common in industry than squeeze casting and it presents the advantage of a much larger cooling rate. Pressure die casting parameters have been successfully adapted to the processing of $\mathrm{Zn}$-based foundry alloys reinforced with mild steel fibres.

Powder metallurgy is the only possible route for reinforcing higher melting point alloys with fibres. A method was designed for dispersing homogeneously carbon fibres within a Cu-base matrix [4]. Metal powders are first dispersed under vigorous stirring in a foam made of distilled water with a surface active agent. The carbon fibres (PAN) are then progressively incorporated in the foam. After filtration and drying, the mats containing the fibres evenly surrounded by metal particles are hot pressed in vacuum at $860^{\circ} \mathrm{C}$ under $17 \mathrm{MPa}$ for 60 to $120 \mathrm{~min}$. (Only composites with random fibre orientation can be prepared by this method). As for composites processed in the liquid state, interface adhesion in composites processed by powder metallurgy can be controlled by alloying additions. These additions can be merely added in the matrix powder before mixing with the fibres.

\section{INTERFACE ADHESION}

The bonding strength at fibre/matrix interfaces can be infered from the distribution of fibre pull-out lengths on fracture surfaces. This approach is more statistical in nature than the methods which have been developed in recent years in the literature and which involve most commonly the measurement of load/displacement curves during the pull-out or the push-out of single fibres. A weak interface adhesion brings about very extensive fibre pull-out whereas a high interface adhesion causes the breakage of the fibres close to the fracture plane of the matrix. This effect has been exploited in quantitative terms for the assessment of the influence of the matrix composition on interface adhesion in a series of composites $\mathrm{Al}+\mathrm{Zn} / \mathrm{C}$ prepared by squeeze casting. In composites with aligned fibres, the increase of fibre pull-out with decreasing interface bonding strength brings about, on a macroscopic scale, an increase of the roughness of the fracture surface after tensile testing in the longitudinal direction. Using cartesian coordinates with the z-axis along the direction of the fibres (i.e. perpendular to the fracture surface), we can measure, as shown in Figure 6, the distribution of $\Delta z$ values for points on the surface separated by $\Delta x=50 \mu \mathrm{m}$. (On the histograms of figure 6 , the first column on the left corresponds to cases with $\Delta \mathrm{z}<8 \mu \mathrm{m}$, i.e. less than the fibre diameter which, on the average, was $10 \mu \mathrm{m}$ ). The maximum occurence of the $\Delta \mathrm{z}$ values shifts continuously when the $\mathrm{Zn}$ content of the matrix increases, reflecting the progressive weakening of the bonding strength. This method provides a quantitative comparison of the interface adhesion within a series of similar composites. 

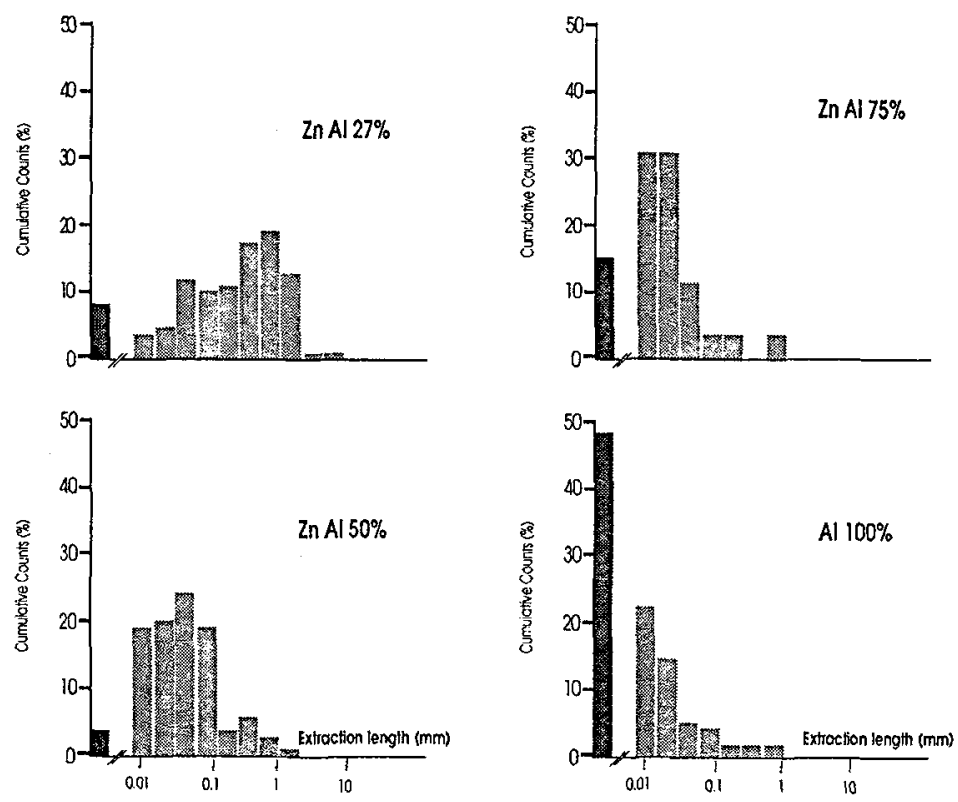

Figure 6 : Histograms of the distributions of step heights $\Delta z$ between points separated by $\Delta \mathrm{x}=50 \mu \mathrm{m}$ on fracture surfaces of composites $\mathrm{Al}+\mathrm{Zn} / \mathrm{C}$ with different $\mathrm{Zn}$ contents

\section{THERMAL EXPANSION}

The measurement of thermal expansion curves is a quite straightforward method for assessing the existence of internal stresses resulting from load transfer at interfaces and for detecting the occurence of plastic yielding in the matrix. This has been demonstrated in the case of composites $\mathrm{Al}+3 \% \mathrm{Mg} / 30 \% \mathrm{SiC}$ (Nicalon) with aligned fibres [5]. In the case of composites with continuous, aligned fibres, the strain of the composite is equal to the strain of the fibres, which is the sum of a thermal strain $\alpha_{f} \Delta T$ and of an elastic strain due to the loading of the fibres by the matrix. At high temperature, the stresses in the fibres balance the stresses causing the matrix to flow plastically in compression during heating and in traction during cooling. These stresses being low at high temperature, it may be assumed the thermal contribution $\alpha_{\mathrm{f}} \Delta \mathrm{T}$ to the fibre strain is equal to the mean of the strains recorded on the heating and cooling parts of the curves. This allows to determine the elastic contribution of the fibre strain. This elastic strain can, in turn, be converted into mean matrix stress by taking into account the volume fraction and Young's modulus of the fibres. During plastic straining of the matrix, the internal stresses follow the temperature dependence of the equivalent flow stress.

A major attribute of MMCs for potential applications is their high thermal conductivity coupled with limited thermal expansion. In addition, the decrease of thermal expansivity which can be achieved by reinforcing a particular alloy depends on the nature, volume fraction, and orientation of the fibres. As an illustration, figure 7 compares the average thermal expansion coefficient between room temperature and $250^{\circ} \mathrm{C}$ for alloy ZA8 and for 4 composites of this alloy. (ZA8 is a $\mathrm{Zn}$-based foundry alloy with nominal composition $8 \% \mathrm{Al}, 1 \% \mathrm{Cu}, 0.02 \% \mathrm{Mg}$, and the balance of $\mathrm{Zn}$ ). The three composites $\mathrm{ZA8} / \mathrm{C}$, ZA8/Saffil, and ZA8/316L contain 
$20 \mathrm{vol} \%$ of randomly oriented fibres whereas the composite ZA8/mild steel contain $12,5 \mathrm{vol} \%$ of aligned steel fibres. The low values measured for composite ZA8/mild steel cannot be accounted for by the law of mixtures. Indeed, the shape of the expansion curve gave evidence of plastic flow of the matrix within the.considered temperature range.

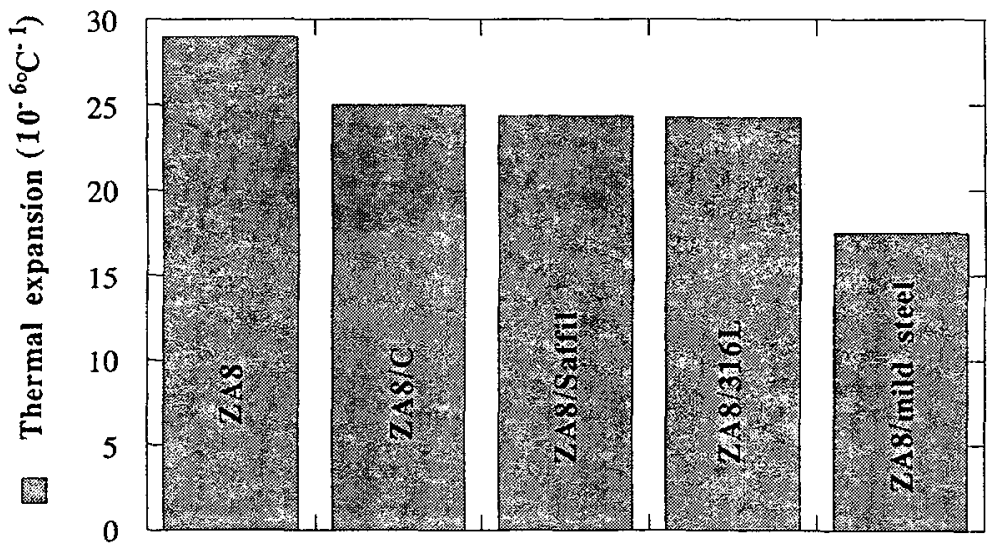

Figure 7 : Comparison of the average thermal expansion coefficient between room temperature and $250^{\circ} \mathrm{C}$ for alloy ZA8 and for 4 composites of this alloy.

\section{FRACTURE TOUGHNESS}

In comparison to the matrix alloy, metal composites present often a reduced ductility and a lower fracture toughness. Actually, for a given matrix alloy, fracture toughness depends very much on the brittleness of the fibres and on the interface bonding strength.

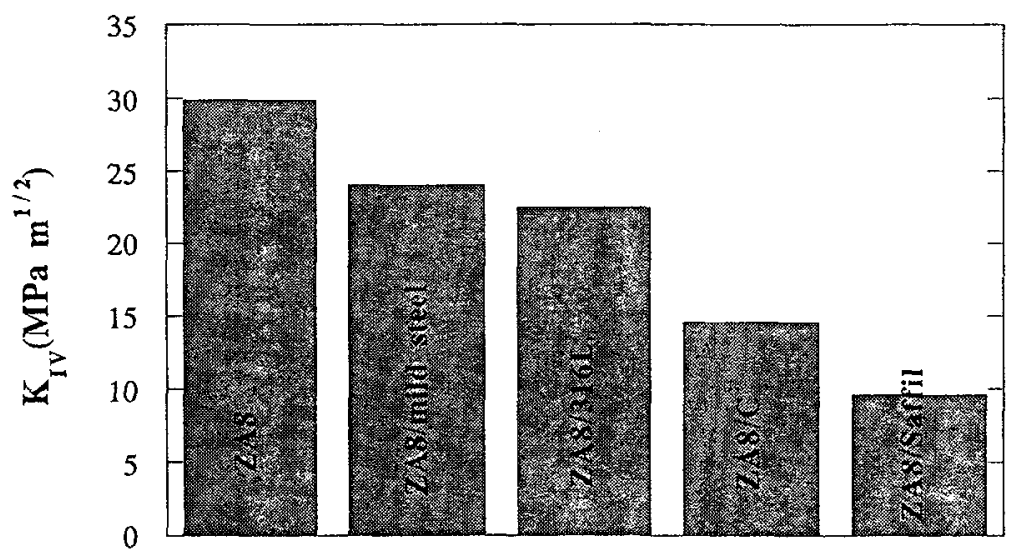

Figure 8 : Comparison of the fracture toughness $\mathrm{K}_{\mathrm{Ic}}$ of ZA8 and of 4 composites of this alloy

As an illustration, figure 8 compares the fracture toughness $\mathrm{K}_{\mathrm{Iv}}$ (measured by the chevron notched short bar method) for alloy ZA8 and for the same three composites as for figure 7. The origin of the toughness differences can be infered by observation of the fracture surfaces in the micrographs of figure 9. (It must be noticed that, at 
room temperature, the cracking mechanism of ZA8 is partly by cleavage, partly by ductile tearing).

Reinforcing ZA8 with alumina (Saffil) fibres causes the largest loss of toughness. Indeed, figure 9a indicates that alumina fibres undergo brittle fracture without pull-out from the matrix. This brittleness facilitates greatly crack extension in the matrix by cleavage.

In contrast, only a fairly limited loss of toughness is obtained with steel or stainless steel fibres. Figure $9 \mathrm{~b}$ shows in this case the occurence of quite large fibre pull-out with evidence of extensive plastic straining and necking of the fibres. This suggests that, in a similar way as in ceramic composites, if the fibres are more ductile than the matrix alloy and if the interface adhesion is low enough, a contribution to toughness may arise from the plastic straining of fibres bridging the crack wake [6]. This contribution should increase when the fibre size increases.

The case of carbon fibres is intermediate between the two other cases. Figure 9c shows evidence of a brittle fracture of the fibres with extensive pull-out. This pullout results from the weak adhesion at $\mathrm{Zn} / \mathrm{C}$ interfaces. Some toughening should arise in this case as a result of the friction stresses during pull-out.

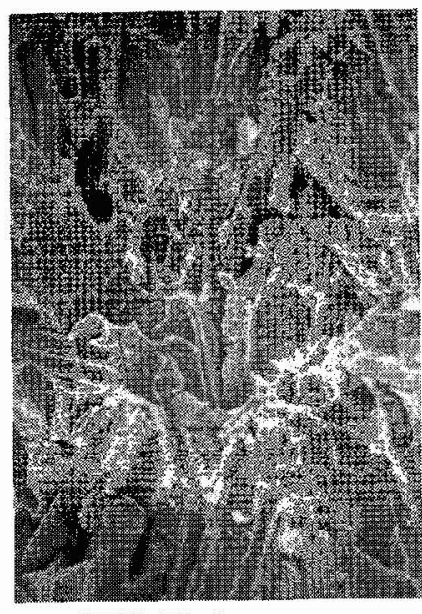

a $\mathbf{2 0} \mu \mathrm{m}$

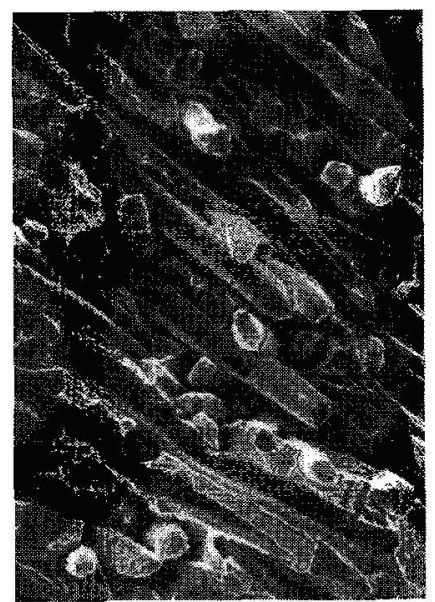

b $50 \mu \mathrm{m}$

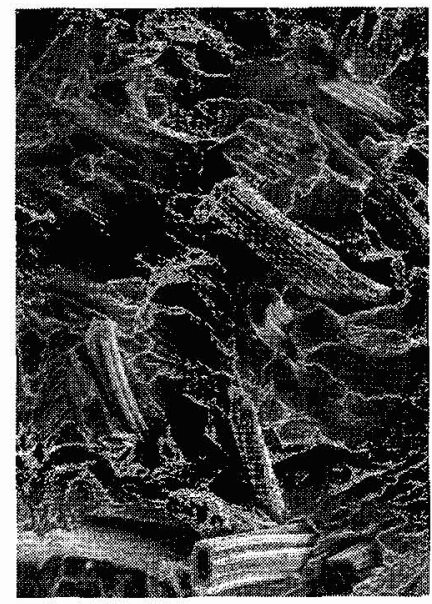

c $50 \mu \mathrm{m}$

Figure 9 : Fracture surfaces of composites ZA8/Saffil (a), ZA8/316L (b), and ZA8/C (c)

Interface decohesion can be beneficial for enhancing the impact strength of composite laminates. This effect has been demonstrated in ZA8 matrix composites reinforced with bidirectional carbon tissues [3]. The highest work of rupture $K_{C}$ of Charpy specimens was observed when the orientation of the tissues in the specimen was such as to induce extensive delamination between the successive plies.

\section{CREEP STRENGTH}

The stationary creep rate of fibre reinforced composites is currently reduced by several orders of magnitude in comparison to that of the unreinforced matrix. In relative terms, creep strength is thus the property for which the improvements 
brought about by the reinforcement are the most spectacular. This benefit can be exploited even at relatively low temperature in parts made of $\mathrm{Zn}-\mathrm{Al}$ foundry alloys for high volume, low cost applications.

Composites ZA8/mild steel have been used for studying in more detail the mechanism of creep strengthening [7]. No early cavitation was observed during creep, which indicates that the interface adhesion is high enough as to allow to maintain stress transfer between the matrix and the fibres. When the temperature and the stress are high enough for allowing the observation of stationary creep, the total elongation of the composite exceeds by far the elastic strain of the fibres. As steel can be considered as non-creeping at the temperature of the test, this indicates that the stress on the fibres is higher than the flow stress at the temperature of the test. Hence, the fibres are deforming plastically at a rate which is governed by the creep of the matrix under a very reduced stress. This mechanism was confirmed by the fact that the creep activation energy of the composites is fairly similar to that of the matrix.

The influence of the fibre diameter on creep strengthening has been studied on a series of composites ZA8/mild steel with random fibre orientation. Figure 10 shows the variation of the steady-state creep rate at $150^{\circ} \mathrm{C}$ as a function of the fibre diameter. The steady-state creep rate of the composites with the smallest fibre diameter $(14 \mu \mathrm{m})$ is more than two orders of magnitude lower than the creep rate of the matrix. However, this creep rate appears to increase rapidly with increasing fibre diameter. The origin of this strong dependence is the subject of ongoing work. This suggests at least that the fibre size needs to be optimized in order to reach the best compromise between fracture toughness and creep strength.

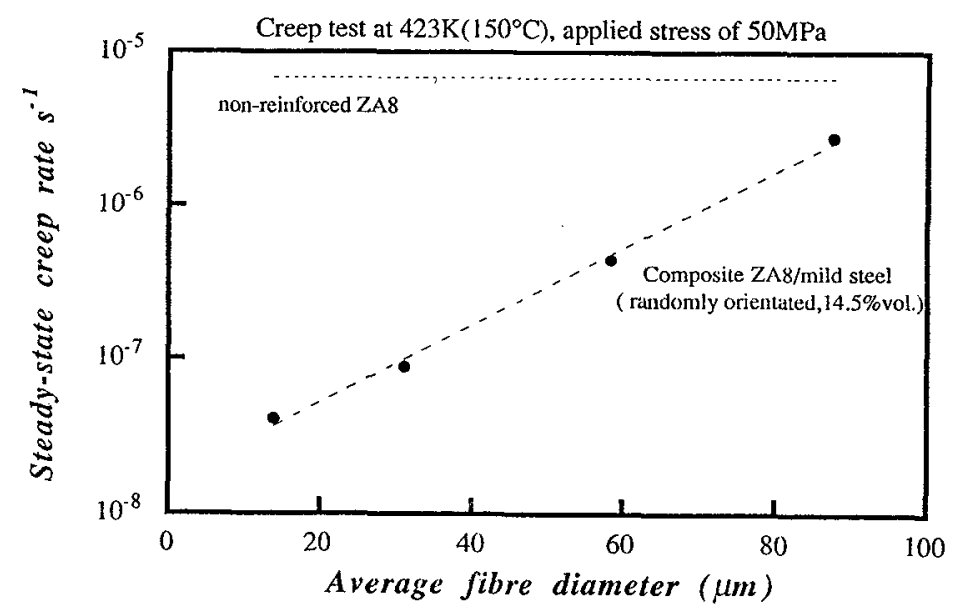

Figure 10 : Variation of the steady-state creep rate at $150^{\circ} \mathrm{C}$ for $\mathrm{ZA} 8 / \mathrm{mild}$ steel composites as a function of the average fibre diameter. The dashed line locates the creep rate of the unreinforced matrix

Both steel fibres and Saffil fibres bring about approximately the same creep strengthening of a ZA8 matrix at $150^{\circ} \mathrm{C}$. Refering to the fracture toughness data of figure 8 , it may be concluded that the best compromise of creep strength versus ductility in $\mathrm{Zn}$-based composites is offered by steel fibre. When considering price in addition, the optimum choice for the reinforcement of zinc-based alloys appears mild steel fibres.

In the case of $\mathrm{Zn} / \mathrm{C}$ composites, the very low adhesion at interfaces appeared detrimental for the creep properties. Indeed, for composites ZA8/C, the measured 
minimum creep rate at $150^{\circ} \mathrm{C}$ was similar to that of the unreinforced matrix. This was found to be due to an early development of creep cavitation at fibre/matrix interfaces, leading to a reduced creep life.

\section{CONCLUSTON}

When the processing conditions are properly controlled, continuously reinforced metal composites present attractive properties from the point of views of thermal expansion and creep strength. In composites with low melting point matrices, the reduction of fracture toughness and ductility typical of metallic composites can be alleviated without affecting the other properties by substituting the ceramic fibres by ductile fibres such as steel fibres. Fibres and processing methods can be used whose cost remains compatible with the price of common $\mathrm{Zn}$-based foundry alloys.

\section{ACKNOWLEDGEMENTS}

The authors are indebted to the collaboration of Dr J. Wégria and to the support of the companies Union Minière and N.V. Bekaert S.A.. Part of this work was also carried out under financial support of the Ministry of Research and Technologies of the Walloon Region and the Office of Science and Policy Programming (SPPS).

\section{REFERENCES}

1. M - A. Dellis, MEng thesis, Université catholique de Louvain, 1989

2. C. Colin, Y. Marchal and F. Delannay, Proceedings EUROMAT 93, in press

3. F. Vescera, J.P. Keustermans, M-A. Dellis, B. Lips and F. Delannay, in "Metal Matrix Composites - Processing, Microstructure and Properties" (N. Hansen, D. Juul Jensen, T. Leffers, H. Lilholt, T. Lorentzen, A.S. Pedersen, O.B. Pedersen and B. Ralph eds) Ris $\emptyset$ National Laboratory, Roskilde, Denmark, 1991, pp 719-724

4. F. Huybrechts and F. Delannay, Powder Metallurgy , 34 (4) (1991) 281- 284

5. D. Masutti, J.P. Lentz and F. Delannay, J. Mater. Sci. Letters 9 (1990) 340-342

6 F. Delannay, B. Lips, M-A. Dellis, M. Van Den Neste, L. Tao and J. Wégria, in "Mechanical Properties and Applications of MMC" (S. Nishijima and C. Bathias eds), The Science and Technology Agency, Tokyo, Japan, 1992, pp119123

$7 \quad$ T. Ling, F. Wégria, and F. Delannay, in preparation 